Artigo original

Hegemonia - Revista Eletrônica do Programa de Mestrado em Direitos Humanos, Cidadania e Violência/Ciência Política do Centro Universitário Unieuro

ISSN: 1809-1261

UNIEURO, Brasília, número 22 (Especial), 2017, pp. 48-25.

Recebido em: 22/7/2017

Avaliado em: 11/8/2017

Aceito em: 13/8/2017

\title{
DESAPOSENTAÇÃO: Um instrumento de retribuição efetiva ao aposentado
}

\author{
brasileiro
}

Antônia Maria Da Silva ${ }^{1}$ e José Felicio Bergamim²

Resumo: Este artigo objetiva discutir e debater acerca da desaposentação em face do ordenamento jurídico brasileiro. Não se pode negar que, em uma sociedade em evolução, novas tendências surgem e buscam se incorporar ao seu direito, restando saber se tais inflexões podem ser benéficas ou maléficas à sociedade estatal. A Constituição Federal/1988 baseia-se na dignidade da pessoa humana, como um de seus princípios fundamentais e, sem dúvida, uma aposentadoria adequada integra esta dignidade pretendida por propiciar aos idosos as condições de manter seu sustento e saúde, sem recorrer a programas governamentais e/ou auxílio de parentes. Na sociedade pátria, tornou-se comum pessoas idosas, já jubiladas, voltarem à situação de ativas para auxiliar no custeio do lar, sendo que em certos casos, a renda desse idoso constituise na base principal do sustento do lar. Quando de seu retorno ao labor, novamente incidem os descontos em favor da Previdência Social, no entanto a atual legislação não permite explicitamente que essas contribuições sejam utilizadas para melhora de seus proventos, consistindo-se em obrigação para o trabalhador, mas não estabelece a devida contrapartida do Estado. Diante desse fato, surge na via jurídica a desaposentação, um instrumento de retribuição econômica do aposentado brasileiro, instituto agora discutido no Legislativo, para possibilitar o otiundignus ao trabalhador, sem que este necessite travar verdadeira batalha nos tribunais para sobreviver dignamente.

Palavras-chave: Desaposentação. Renúncia. Retribuição Econômica. Seguridade Social.

Abstract: This paper aims to discuss and debate about the desaposentação in the face of Brazilian law. One can not deny that in a society in evolution, new trends emerge and seek to incorporate their right, leaving whether such inflections can be beneficial or harmful to the state society. The Federal Constitution / 1988 is based on the dignity of the human person as one of its fundamental principles and undoubtedly an adequate retirement integrates this required dignity by providing the elderly able to maintain their livelihoods and health without resorting to government programs and / or assistance from relatives. In the homeland society, it has become common elderly, already jubilates, return to active status to assist in the cost of the home, and in some cases, income elderly that constitutes the main home of the livelihood base. Upon his return to work again focus discounts in favor of Social Security, however the current legislation does not explicitly allows these contributions are used for improvement of their earnings if consisting in obligation for the worker, but cannot establish correct hand of the state. Given this fact, comes in via the legal desaposentação. An economic retribution instrument of the Brazilian

\footnotetext{
${ }^{1}$ Bacharel em Direito e Economista.

${ }^{2}$ Doutor em Ciências Militares, Professor do Centro Universitário Estácio-FACITEC.
} 
Artigo original

Hegemonia - Revista Eletrônica do Programa de Mestrado em Direitos Humanos, Cidadania e Violência/Ciência Política do Centro Universitário Unieuro

ISSN: 1809-1261

UNIEURO, Brasília, número 22 (Especial), 2017, pp. 48-25.

retired, institute now discussed in the Legislature, to enable otiundignus the worker, without this need to catch real battle in the courts to survive with dignity.

Keywords: Unretirement. Disclaimer. Economic Retribution. Social Security.

\section{INTRODUÇÃO}

Este artigo trata sobre a desaposentação, um instrumento de retribuição econômica do aposentado no contexto do ordenamento jurídico brasileiro, buscando analisar suas implicações no sistema da Previdência Social pátrio. $\mathrm{Na}$ análise deste instituto, abordam-se as áreas do direito constitucional, administrativo, previdenciário e do trabalho, buscando-se verificar sua viabilidade quanto aos aspectos legais tendo em vista que a Corte Máxima ainda não se posicionou consistetemente acerca da legalidade do instrumento jurídico. Ressaltam-se, ainda, as divergências na doutrina, jurisprudencia e no âmbito do Poder Público, quer no Executivo e/ou no Legislativo.

Suscita-se a viabilidade do instituto diante dos princípios da coisa julgada, direito adquirido e equilíbrio econômico-financeiro, já que a aposentadoria trata-se de ato jurídico perfeito e que ao desaposentar, o beneficiário estaria contando tempo de contribuição anterior, a fim de adquirir no futuro uma nova aposentadoria mais benéfica. Por outro lado, o princípio da dignidade da pessoa humana (DPH) demonstra ser corolário da aplicabilidade da desaposentação, uma vez que ele se constitui num dos fundamentos basilares da República Federativa do Brasil.

Analisam-se a legislação e doutrina, enfocando-se a legalidade, coisa julgada, o direito adquirido e ato jurídico perfeito, com o fito precípuo de se constatar aplicabilidade do instituto, bem como outras implicações e impactos na Previdência Social e sociedade pátria, tendo em vista o equilíbrio econômico-financeiro e atuarial da seguridade social nacional, bem como outros reflexos possíveis nas futuras aposentadorias.

\section{DOS DIREITOS SOCIAIS}

Os direitos sociais são conquistas progressivas resultantes das pressões sociais ao longo dos tempos, assim, podem ser encontradas referências em códigos como o de Talmude, Código de Hamurabi, Código de Manu. Na Grécia antiga há o surgimento de associações denominadas de collegia ou sadalitia, compostas por pequenos artesões com o objetivo de compor um fundo destinado aos custos funerários dos associados. 
Artigo original

Hegemonia - Revista Eletrônica do Programa de Mestrado em Direitos Humanos, Cidadania e Violência/Ciência Política do Centro Universitário Unieuro

ISSN: 1809-1261

UNIEURO, Brasília, número 22 (Especial), 2017, pp. 48-25.

Tal mobilização popular fez o governo modificar seu tratamento com o povo, como exemplo cita-se a edição na Inglaterra da Lei dos Pobres, em 1601, instituindo a contribuição obrigatória e universal para custear ações de assistência social, seguida em 1789, pela Declaração dos Direitos do Homem e do Cidadão, universalizando a seguridade social, que se dissemina, em 1948, com a Declaração Universal dos Direitos Humanos.

$\mathrm{Na}$ evolução do direito de seguridade, destaca-se, ainda, o ato alemão de 1883 instituindo a composição de custeio tríplice - Estado, empregados e empregadores - em busca do equilíbrio financeiro do sistema. A carta mexicana de 1917, com visão neoconstitucional, representou evolução ao conferir à seguridade social status constitucional.

No que tange ao Brasil, o reconhecimento dos direitos sociais relativos à previdência tem sua origem em 1543, com a criação por Braz Cubas, do plano de pensão para os empregados da Santa Casa de Santos, sob regime previdenciário contributivo fechado. Atualmente, o texto constitucional trata dos direitos sociais no Título II, Capítulo II, art. $6^{\circ}$ ao 11 , sendo estas prestações positivas pautadas na igualdade social e solidariedade. Nesse sentido, José Afonso da Silva apud Paulo e Alexandrino (2013. p. 244), cita que as prestações positivas são deveres do Estado que possibilitam aos mais fracos uma condição de vida mais igualitária com o restante da população, minorando os fatores de desigualdade.

Observa-se que parte da doutrina considera os direitos sociais como cláusula pétrea, devido ao princípio da $\mathrm{DPH}$, base da $\mathrm{CF} / 88$, porém tal status não é unânime, haja vista que o constituinte originário ao definir o rol de cláusulas pétreas apenas referiu-se a direitos e garantias individuais, bem como ainda se mostra pendente pronunciamento do Supremo Tribunal Federal (STF) quanto aos direitos sociais serem ou não assim considerados.

No entanto, julgados do STF acolhem os direitos sociais como o mínimo existencial necessário para DPH (BRASIL. STF. 2001), sendo ilícito ao Estado se furtar dessa obrigação, pois consistiria, na opinião de Garcia (2014. p. 1401), em retrocesso social, bem como ofensa ao Pacto Internacional dos Direitos Econômicos, Sociais e Culturais, do qual o Brasil é signatário.

Assinala-se, ainda, o implícito princípio da proibição de retrocesso social que, consoante Canotilho apud Paulo e Alexandrino (2013. p. 259), assegura que uma vez regulado dispositivo constitucional de ordem social, não se pode retroceder na matéria no sentido de anular, abolir ou reduzir a eficácia desse dispositivo.

Sem dúvidas a seguridade social encontra-se amparada por este princípio por consistir em um conjunto integrado de ações estatais e da sociedade, com o fito de assegurar os 
Artigo original

Hegemonia - Revista Eletrônica do Programa de Mestrado em Direitos Humanos, Cidadania e Violência/Ciência Política do Centro Universitário Unieuro

ISSN: 1809-1261

UNIEURO, Brasília, número 22 (Especial), 2017, pp. 48-25.

direitos relativos à saúde, previdência e assistência social, conforme previsão constitucional, assim, todas as ações que visem amenizar os riscos sociais não podem sofrer retrocesso.

Baltazar e Rocha (2004. p.33) entendem que esses riscos são inerentes a todos os indivíduos e são capazes de desajustar as condições normais de vida, no mesmo sentido Assis (1950, p.28, apud Dias, 2010. p. 37) assevera que o risco social expõe ao perigo a própria sociedade, ocasionando necessidades em todas as áreas, desse modo e, em consonância com o art. $1^{\circ}$ da Lei $n^{\circ} 8.212 / 91$ (BRASIL. 1990), a seguridade social regula-se por intermédio dos seguintes princípios: universalidade objetiva e subjetiva; seletividade e distributividade; irredutibilidade do valor; equidade; diversidade da base de financiamento; caráter democrático e descentralizado.

Os princípios destacados destinam-se a garantir as prestações a todas as pessoas, rurais e urbanas, o mesmo nível de ganho, mas corrigindo distorções entre os mais necessitados, ao mesmo tempo em que assegura a irredutibilidade do poder de compra, impedindo assim a divergência entre quem tem maior e menor poder contributivo.

Em se tratando de Previdência Social, o pioneiro registro legal no Brasil é o Decreto $\mathrm{n}^{\circ}$ 9.912-A, de 1888, que regulava o direito à aposentadoria dos empregados dos Correios, estabelecendo como pressupostos a idade mínima de 60 anos e tempo de serviço efetivo em 30, no entanto, o marco previdenciário é o Decreto n 4.682, de 1923, Lei Elói Chaves, que criou uma Caixa de Aposentadoria e Pensões para os empregados de cada empresa ferroviária. Após sua edição várias modificações foram instituídas até se chegar ao modelo vigente nos dias atuais, com previsão constitucional nos art. 40, 201 e 202, CF/88.

O objetivo da Previdência Social é garantir qualidade de vida para o administrado que não tem mais condições de prover o próprio sustento, seja por força maior, falta de condições físicas ou mentais. Ela é caracterizada pela gestão governamental, compulsoriedade e repartição simples, em que a geração atual fomenta os rendimentos da geração pretérita.

Foram criados três regimes de previdência para melhor gerir os valores recolhidos e garantir os objetivos sociais estabelecidos. Os referidos regimes são:

a) Regime Geral de Previdência Social (RGPS) - denominado por Carvalho (2012. p. 01), de “a previdência da grande massa de trabalhadores". É compulsório, por força constitucional, a todos aqueles que não estão vinculados aos demais regimes e venham a exercer atividade econômica, excetuando-se os segurados facultativos como as donas de casa e desempregados. 
Artigo original

Hegemonia - Revista Eletrônica do Programa de Mestrado em Direitos Humanos, Cidadania e Violência/Ciência Política do Centro Universitário Unieuro

ISSN: 1809-1261

UNIEURO, Brasília, número 22 (Especial), 2017, pp. 48-25.

b) Regime Próprio de Previdência Social (RPPS) - Segundo o autor supra, os agentes públicos têm sua previdência regulamentada pela $\mathrm{CF} / 88$, art. 40 e, pela Lei no $9.717 / 98$ ou estatutos específicos. Similar ao RGPS possui caráter contributivo, obrigatório e solidário, abrangendo os servidores ativos, inativos e pensionistas do quadro de funcionários da União, Estados, Distrito Federal e Municípios, suas autarquias e fundações e, deve garantir a mesma proteção previdenciária do RGPS, ou seja, aposentadoria e pensão.

Aos integrantes desse regime é garantida a aposentadoria em três modalidades compulsória, invalidez ou voluntária. A compulsória ocorre aos 70 anos, independentemente do tempo de contribuição ou solicitação do servidor, já a aposentadoria por invalidez só acontece por invalidez permanente e pode garantir proventos proporcionais ou integrais.

Para aposentadoria voluntária, o servidor deve completar 10 anos de efetivo serviço, 05 anos no cargo efetivo, além de 35 de contribuição e 60 anos de idade para homens e um lustro a menos no tempo de contribuição e idade para mulher. Para proventos proporcionais, não se exigem os 35 anos de contribuição. Esta categoria também abarca o militar, que paga a denominada de Pensão Militar cuja função é custear sua aposentadoria e a pensão dos dependentes. O militar tem aposentadoria integral após 30 anos de efetivo serviço.

c) Regime de Previdência Complementar (RPC) - Carvalho (2012. p. 01) explica que o regime de previdência complementar ou privada é previsto pelo art. 202, CF/88 e regulamentado pela Lei Complementar no 108/2001, sendo a adesão voluntária e contratual, com função complementar à Previdência Social. Possui, na lição de Soares (2012. p. 01), um fundo de reserva formado por capitalização, sendo devolvido ao associado o saldo acumulado quando de sua aposentação em parcela única ou em mensalidades.

O RPC possui as modalidades aberta e a fechada, ambas com o mesmo modus operandi, diferindo no público alvo, enquanto a primeira é acessível a qualquer pessoa, a segunda é restrita aos empregados de uma empresa, agentes públicos, associados ou membros de pessoas jurídicas de caráter profissional, classista ou setorial e, a partir de 2003, os trabalhadores vinculados a entidades como sindicatos, cooperativas e órgãos de classe.

\section{INSTITUTO DA APOSENTADORIA}

A aposentadoria, direito social dos trabalhadores rurais e urbanos, estabelecido no inciso XXIV, do art. $7^{\circ}$, da $\mathrm{CF} / 88$, deve ser concedida obedecendo a parâmetros estabelecidos 
Artigo original

Hegemonia - Revista Eletrônica do Programa de Mestrado em Direitos Humanos, Cidadania e Violência/Ciência Política do Centro Universitário Unieuro

ISSN: 1809-1261

UNIEURO, Brasília, número 22 (Especial), 2017, pp. 48-25.

pelo legislador nas diversas modalidades, assim encontram-se no $₫ 1^{\circ}$, do art. 40 e $\int 7^{\circ}$, do art. 201, CF/88 (BRASIL. 1988) os requisitos mínimos para aposentadoria em cada caso.

Seu conceito pode ser melhor encontrado no $\int 2^{\circ}$, art. 453, da CLT (Brasil. 1943), assim como no Dicionário Técnico Jurídico (2010), Vocabulário Jurídico (2000.) e, no sítio da Fundação Fiocruz (sine data. p. 1), definido como a passagem do trabalhador para a inatividade com extinção definitiva do vínculo empregatício, por incapacidade física ou por atingir a idade legal.

Esse tempo de afastamento deve seguir regras que garantam o equilíbrio financeiro e atuarial, sendo assim, foram criadas modalidades de aposentadoria, cada qual com sua regulamentação conforme segue:

Aposentadoria voluntária integral - Modelo em que o servidor, por vontade própria, solicita sua retirada do serviço ativo. É concedida quando conjugado o binômio tempo/idade. Em se tratando de servidores público, a alínea "a”, do inciso III, $\ 1^{\circ}$, art. 40, da CF/88 regula o referido binômio e exige tempo mínimo de 10 anos de efetivo serviço, sendo cinco no cargo efetivo que se dará a aposentadoria, exigência julgada lícita pelo STF (BRASIL. 2011. p. 935), em virtude do equilíbrio financeiro. Já em sede infraconstitucional as Leis 8112/90 (BRASIL, 1990) e 8213/91 (BRASIL, 1991), disciplinam os mesmos requisitos para aposentadoria voluntária, com pequenas alterações em razão de ações afirmativas, assim, a mulher aposenta-se com 5 anos a menos de contribuição, mas em se tratando de professores a redução atinge a ambos os sexos. Para os trabalhadores rurais do regime de economia familiar a redução incide sobre a idade para ambos os sexos.

Durante o governo Fernando H. Cardoso foi criado o Fator Previdenciário (sine data. p. 1), reputado como uma fórmula para desestimular aposentadorias precoces vez que computa a expectativa de vida da população - conforme IBGE - tempo de contribuição, alíquota de contribuição e a idade na data de aposentadoria. Essa fórmula obriga maior tempo de permanência na ativa para atingir 100\% do benefício, isto porque a melhora na expectativa de vida age como fator redutor do valor a ser pago pela previdência, gerando inevitável perda de poder aquisitivo, motivo pelo qual corre projeto tendente a acabar com tal fator.

Aposentadoria por invalidez integral (sine data. p. 1) e proporcional - A primeira ocorre, no magistério de Ibrahim (2011. p. 31), quando perícia médica julga que a moléstia grave, incapacitante ou contagiosa, acometida pelo trabalhador, representa risco para si ou para outros. É necessário que o acidente, moléstia profissional ou doença grave tenham relação direta com a atividade profissional para os proventos serem pagos integralmente, ou seja, se faz necessário 
Artigo original

Hegemonia - Revista Eletrônica do Programa de Mestrado em Direitos Humanos, Cidadania e Violência/Ciência Política do Centro Universitário Unieuro

ISSN: 1809-1261

UNIEURO, Brasília, número 22 (Especial), 2017, pp. 48-25.

provar a relação de causa e efeito, somente sendo possível a aposentadoria por mal pré-existente nos casos em que a atividade laboral venha a agravar a situação. A segunda se caracteriza por não haver causa e efeito, obrigando o pagamento de proventos proporcionais, mesmo presente a incapacidade laboral ou risco. Ambas estão previstas na Lei 8112/90.

Zarzana (2014. p. 39) salienta que esse status pode ser revogado com o retorno voluntário ao trabalho ou por atestado de junta médica competente. O novo laudo confirmando a situação de aposentado, readaptando a nova função compatível com a moléstia sofrida ou permitindo o retorno as funções antigas, pode ser requerido pelo trabalhador ou pela administração para reavaliação periódica, conforme se extrai do art. 188, Lei 8112/90.

Aposentadoria compulsória (sine data. p. 1) - Esta modalidade possui duas vertentes. A primeira diz respeito ao servidor público - homem e mulher - que deve ser aposentado compulsoriamente aos 70 anos, com proventos proporcionais, qualquer que seja seu tempo de serviço, conforme se extrai do inciso II, $₫ 1^{\circ}$, Art. 40, CF/88. A segunda se aplica ao trabalhador do RGPS que deve conjugar o binômio tempo/contribuição, respeitando o tempo de carência e a redução de 5 anos para mulher, conforme Lei 8213/91, e a empresa pode, mas não é obrigada, a pedir a aposentadoria compulsória do trabalhador.

O período de carência do art. 25, da Lei 8213/91 e aplicável ao trabalhador do RGPS é de 180 meses e, devido ao fato de compulsoriamente ocorrer a aposentadoria proporcional, se sobrevier posteriormente qualquer das moléstias especificadas do art. 186, Lei 8112/90, passa o beneficiário a condição de inválido com proventos integrais.

Aposentadoria proporcional por idade - Insculpida no art. 40, CF/88 e, no art. 186, da Lei 8112/90, esta modalidade permite a aposentadoria a partir dos 65 anos, se homem, e 60 anos, se mulher, além dos requisitos de tempo do art. $40 \mathrm{CF} / 88$. Pela inocorrência do desejado tempo de contribuição - 30 anos - aos rendimentos serão proporcionais. Para o trabalhador do RGPS, a Lei 8213/91 trata do assunto nos art. 48 a 50, estabelecendo os mesmos parâmetros que o art. 186 supra, com ressalva para o trabalhador rural que terá a idade mínima reduzida em 05 anos se comprovar ter trabalhado o tempo mínimo de 15 anos.

\section{INSTITUTO DA DESAPOSENTAÇÃO}

A desaposentação é a renúncia à aposentadoria aproveitando o tempo de fruição da aposentadoria pretérita para contagem em outra nova jubilação mais benéfica, decorrente de outra atividade profissional, em qualquer regime previdenciário, no entanto, para Martinez (2005. 
Artigo original

Hegemonia - Revista Eletrônica do Programa de Mestrado em Direitos Humanos, Cidadania e Violência/Ciência Política do Centro Universitário Unieuro

ISSN: 1809-1261

UNIEURO, Brasília, número 22 (Especial), 2017, pp. 48-25.

p.434) “desaposentação não é o inverso da aposentação, mas o restabelecimento do cenário pretérito, retroagir ao estágio em que se encontrava quando do deferimento da prestação."

Para Ibrahim (2011. p. 35.), assim como Colnago (2005, p. 784-793.), desaposentação consiste em liberar o tempo de serviço usado anteriormente na aquisição de uma aposentadoria, para averbação em outro regime, ou no mesmo, com acréscimo de novo tempo e melhora nos rendimentos.

Apesar de a desaposentação não estar contemplada, expressamente, no ordenamento jurídico brasileiro, vale a lição de Ibrahim (2011. p. 65) ao afirmar que não existe necessidade de autorização expressa para o exercício de um direito desde que esse não viole preceitos constitucionais. Acerca dos valores constitucionais, Salvador (2011, p. 08, apud SOUZA, 2015. p. 23) diz que a desaposentação representa "meio eficaz e válido para a convolação de primados constitucionais", ou seja, é modo de alcançar os objetivos da CF/88.

No entanto, há vozes na doutrina que refutam o emprego da desaposentação por falta de previsão legal, como Macedo (1997, p. 309-316, apud SOUZA, 2015. p.24), a quem somente seria lícito tal instituto com lei expressa. Com a mesma opinião Colnago (2005, p. 793, apud SOUZA, 2015. p. 26) argumenta a necessidade de um instrumento jurídico em virtude da paridade de formas, já que a aposentadoria se encontra prevista no mundo jurídico e a desaposentação carece de tal formalidade.

Em que pese a falta de previsão legal expressa, vislumbra-se que a desaposentação apresenta-se como um instituto que legitima a DPH como justiça social, por proporcionar uma melhoria financeira na aposentadoria do beneficiado em decorrência de um acréscimo no padrão de vida capaz de mitigar a redução do poder aquisitivo real.

Nos diversos debates a respeito da desaposentação, chamou a atenção o detalhe sobre a natureza jurídica se se trata de renúncia, abandono ou desistência. Uma vez que o abandono se caracteriza pela intenção clara de abandono do direito, acarretando consequências opostas à aquisição destes e, na desistência ocorre a manifestação voluntária do titular do direito pelo não exercício, resta verificar o conceito de renúncia.

A renúncia é ato unilateral no qual o titular de direito disponível o abdica, sem necessidade de consentimento de um terceiro. Diniz (1998, p. 36) afirma ser ato explícito e voluntário de abdicação a direito próprio, podendo ser típica ou própria, não havendo o exercício do direito e nem a transferência deste à terceiro, nesse liame, assevera Salvador (2014. p. 38) ser a renúncia: "ato unilateral do agente, consistente no abandono voluntário de um direito ou de seu exercício; é ato, portanto, que independe da aquiescência de outrem. ” 
Artigo original

Hegemonia - Revista Eletrônica do Programa de Mestrado em Direitos Humanos, Cidadania e Violência/Ciência Política do Centro Universitário Unieuro

ISSN: 1809-1261

UNIEURO, Brasília, número 22 (Especial), 2017, pp. 48-25.

Por fim, tanto Martinez (2014. p. 52) quanto a Turma Recursal de Santa Catarina (2004) afirmam que o segurado abdica de seu direito ao benefício, mas pode usar o tempo para a aquisição de novo direito, pois esse ato não põe fim ao direito, apenas suspende o seu exercício. Destarte, na desaposentação ao desconstituir o ato da aposentadoria não há abandono ou desistência, visto que num futuro se almeja uma nova aposentadoria com a junção do tempo da desfeita e do novo tempo contributivo, contudo, mais vantajosa do ponto de vista econômico.

Igualmente controverso se apresentou a necessidade de devolução dos valores percebidos durante a primeira aposentadoria, como ato necessário para a concessão de nova jubilação. Esse tema aguarda julgamento pelo STF, nesse ínterim, as vozes divergentes continuam apresentando argumentos favoráveis ao seu ponto de vista.

Os juristas a favor da devolução se apoiam em julgados de tribunais federais, a exemplo: TRF-3 (2011); TRF-5 (2014) e da Turma de Uniformização de Jurisprudência dos Juizados Especiais Federais, in verbis:

PEDIDO DE UNIFORMIZAÇÃO NACIONAL -
DESAPOSENTAÇÃO - NECESSIDADE DE DEVOLUÇÃO DOS
PROVENTOS JÁ RECEBIDOS. 1. A desaposentação, isto é, a
desvinculação voluntária de aposentadoria já concedida e usufruída,
somente é possível mediante devolução dos proventos já recebidos. 2.
Pedido de Uniformização apresentado pela parte autora improvido.
(BRASIL, 2011)

Em contrapartida, a maioria dos juristas, apoiados em decisões exaradas por diversos tribunais entende que a devolução seria abusiva, já que não houve ilegalidade quando da concessão da aposentadoria original, bem como citam a premissa de que os proventos têm natureza alimentar, portanto irrepetíveis. Igualmente, a jurisprudência do Superior Tribunal de Justiça (STJ) posiciona-se pela desnecessidade de devolução dos proventos uma vez que não haja ilicitude quanto à concessão da desaposentação, o que descaracterizaria enriquecimento ilícito. (STJ. 2014).

Ainda na linha das vozes doutrinárias que propugnam pela desnecessidade de restituição dos valores recebidos, pode ser chamado Salvador (2014. p. 59-60) que considera a desaposentação como um recálculo de proventos em virtude das contribuições extras.

Entende-se que obrigar a devolução dos proventos para obter a desaposentação, inviabiliza o instituto e vilipendia o caráter de natureza alimentar irrepetível, oriundo da verba de 
Artigo original

Hegemonia - Revista Eletrônica do Programa de Mestrado em Direitos Humanos, Cidadania e Violência/Ciência Política do Centro Universitário Unieuro

ISSN: 1809-1261

UNIEURO, Brasília, número 22 (Especial), 2017, pp. 48-25.

aposentadoria. Verifica-se, ainda, que exigir a devolução tornaria inviável a melhora almejada, pois o contribuinte se veria obrigado a devolver alta soma - somatório de anos na condição de aposentado - para receber valor não muito significativo, visto que seriam poucos a alcançar o teto da previdência e seguramente o valor a restituir estaria além desse teto.

Este assunto não encontra consenso devido ao risco ao equilíbrio atuarial e financeiro do regime previdenciário. Lima (2010. p. 01) esclarece que esse risco fez surgir 4 vertentes quanto à devolução dos valores recebidos. "a primeira, sustentando a não devolução/restituição; a segunda defende a devolução parcial; a terceira defende a devolução integral e a quarta defende a devolução apenas do necessário".

As correntes que defendem a devolução, parcial ou total, têm como preocupação a possibilidade de provocar prejuízo a terceiros ou ao regime de destino, uma vez que o regime novo não recebeu os aportes necessários e deve arcar com a nova aposentadoria, porém, o mesmo autor sustenta a inexistência de prejuízo se a reaposentação for no mesmo regime e, se o contribuinte trocar de regime, deve ser feita devolução apenas do suficiente para a manutenção do equilíbrio financeiro.

Destarte, exigir do aposentado a devolução de valores recebidos é desferir golpe mortal nas economias de pessoas já ofendidas pelo fator previdenciário que reduz o valor a ser recebido. Nesse liame, a interrupção do benefício entende-se como possível, haja vista que o desaposentado voltará à atividade remunerada. Quanto às verbas indenizatórias, tais benefícios poderiam ser preservados, mas corrigidos atuarialmente, sendo abatidos dos direitos inerentes à aposentadoria definitiva.

Quanto à disponibilidade da aposentadoria, bem como os requisitos necessários para nova aposentação, Souza (2015. p. 59), leciona que a primeira das exigências é a continuidade do exercício laboral com aportes ao INSS, mesmo após ter sido concedida a jubilação.

Quando o aposentado exerce atividade remunerada, continua obrigatoriamente vinculado ao RGPS ou RPPS de sua atividade, recolhendo valores mensais aos cofres públicos, no entanto, o Estado somente tem por obrigatoriedade conceder-lhe o salário-família e reabilitação profissional, conforme previsão do $\int 2^{\circ}$, art. 18, Lei 8213/91. Com base na mesma lei, é ilegal a concessão de dupla aposentadoria, motivo pelo qual a desaposentação se mostra como meio justo para garantir a retribuição aos aportes.

O segundo requisito é ganhar menos do que o teto previdenciário, atualmente estabelecido em $\mathrm{R} \$$ 4.673,41 (Quatro mil, seiscentos e setenta e três reais e quarenta e um 
Artigo original

Hegemonia - Revista Eletrônica do Programa de Mestrado em Direitos Humanos, Cidadania e Violência/Ciência Política do Centro Universitário Unieuro

ISSN: 1809-1261

UNIEURO, Brasília, número 22 (Especial), 2017, pp. 48-25.

centavos). Não é lógico gastar em um processo para ter ganho irrisório, ou até mesmo déficit no final, assim, deve ser considerada a possibilidade de ganho e perda no processo.

Conforme citado anteriormente, um dos requisitos citados como necessários para a desaposentação seria a previsão legal, no entanto não existe dispositivo para tratar o assunto, sendo a lacuna preenchida pelo Poder Judiciário em virtude da omissão legislativa. A única modalidade de desaposentação existente na legislação está na seção I, capítulo II, Lei 8112/90 que trata da aposentadoria por invalidez, sendo prevista a reversão com o simples retorno do indivíduo à prática laboral remunerada ou por nova avaliação da Junta Médica Oficial. Em qualquer caso ocorre o imediato cancelamento dos pagamentos e considera-se a contagem do tempo de contribuição anterior para uma futura concessão de nova aposentadoria.

A desaposentação não pode ser algo disforme, então preleciona Martinez (2014. passim) que o instituto deve se submeter ao interesse público, não sendo lícito ofender o equilíbrio atuarial e financeiro, pelo que são características necessárias:

Aproveitamento do tempo de serviço anterior. A contagem do tempo anterior deve ser somada com a posterior à aposentadoria primária, desta maneira representa vantagem ao trabalhador e consonância com a legislação pátria a qual impede a revisão in pejus.

Diferenciação do instituto da renúncia. Já explicitado anteriormente, não se trata de renunciar ao direito, mas sim a aposentadoria, voltando a ativa para, imediatamente, requerer outra aposentadoria considerando os valores aportados no período de jubilação.

Imprescritibilidade. Não incidência de prescritibilidade em razão de não se tratar de uma revisão, mas de uma nova aposentadoria, com acréscimo de contribuições feitas no decorrer da antiga aposentadoria, assim inaplicável o caput, art. 103, da Lei 8213/91.

Titularidade do aposentado. Por se tratar de direito individual somente o titular do direito pode a ele renunciar ou buscar alteração, mesmo que seja para sua melhora.

Por fim, devolução do valor recebido. Epicentro de uma discussão ainda sem caminho definido, a devolução dos valores recebidos será resolvida pelo STF que caracterizou o caso como de repercussão geral, tal sua influência na vida da sociedade. Para o autor supra, a devolução inviabiliza totalmente a fruição do direito.

Não aguardo de decisão quanto ao tema, os apoiadores da concessão citam outros países para subsidiar suas alegações, porém, como assevera Martinez (2014. p. 38), "são raras as manifestações doutrinárias e legislativas em outros países, embora se acolha algo sobre renúncia.” Em que pese essa ausência de manifestações, seria possível uma total reformulação, ou adaptação, do sistema previdenciário nacional baseado em experiências de sucesso encontradas 
Artigo original

Hegemonia - Revista Eletrônica do Programa de Mestrado em Direitos Humanos, Cidadania e Violência/Ciência Política do Centro Universitário Unieuro

ISSN: 1809-1261

UNIEURO, Brasília, número 22 (Especial), 2017, pp. 48-25.

no Chile, Canadá ou Portugal, neste último, Ibrahim (2011. p. 88), assim como Pierotti (2009. p.198), citam que o tempo de contribuição pós-aposentadoria é automaticamente utilizado para recálculo anual da aposentadoria, até que se atinja o limite imposto por lei.

No Chile, menos paternalista, o Estado assume a gestão geral dos fundos de pensão, mas a administração efetiva corre por conta de empresas particulares credenciadas para tal fim. Outra diferença é que no Brasil o fundo governamental é único e deve ser repartido por todos, enquanto no país vizinho a conta é feita em nome do trabalhador e este pode portar seu saldo para a administradora de sua preferência, sendo permitidos aportes extras para acelerar a jubilação bem como a contratação de fundos complementares.

Naquela nação inexiste desaposentação, no entanto o aposentado por invalidez que continue trabalhando pode pagar ao fundo de pensão para incrementar o valor recebido como pensão, assim como o trabalhador que continue trabalhando após a jubilação pode deixar de contribuir para o fundo de pensão, passando a recolher apenas para o fundo de saúde. Previsão do art. 69, do Decreto-Lei 3.500/1980 da Lei Chilena. (CHILE. 1980).

Outrossim, nos EUA as contribuições vertidas após a aposentadoria são automaticamente usadas para recálculo do benefício, diferindo da Espanha apenas por esta não permitir o retorno à atividade (PIEROTTTI, 2009. p. 198).

No magistério de Ibrahim (2011. p. 93) o Canadá não prevê a desaposentação, prefere pagar um incentivo para que o administrado retarde sua aposentação, importante diferenciação com o Brasil que adotou o fator previdenciário, uma penalização, para obrigar o trabalhador a postergar a jubilação. No país nortista, se o beneficiário resolver retardar sua jubilação, será pago um acréscimo ao valor referência, podendo chegar a um aumento de até $70 \%$, sendo a idade limite para aposentação 70 anos.

\section{O PODER PÚBLICO E A DESAPOSENTAÇÃO}

Ainda que seja uma aspiração do povo, a desaposentação não pode ocorrer à revelia dos poderes constituídos, desta feita, necessário se faz verificar como os três poderes da República Federativa do Brasil têm se pronunciado quanto ao tema, principalmente em virtude da grande demanda judicial em torno deste e, conforme artigo da Revista Isto É (2012. passim), a grande demanda de idosos que retornam ao mercado de trabalho, para auxiliar na manutenção do lar ou realizar antigos sonhos, se constitui em importante força econômica, nesse cenário torna-se 
Artigo original

Hegemonia - Revista Eletrônica do Programa de Mestrado em Direitos Humanos, Cidadania e Violência/Ciência Política do Centro Universitário Unieuro

ISSN: 1809-1261

UNIEURO, Brasília, número 22 (Especial), 2017, pp. 48-25.

muito importante compreender a importância do instituto da desaposentação, vez que pode significar diferença fundamental na qualidade de vida do jubilado e sua família.

Devido à demanda judicial, o assunto despertou o interesse do Poder Legislativo, que apresentou, entre 1997 e 2002, vários projetos de lei ainda em discussão no Congresso Nacional. A tônica atual é a alteração no texto da Lei 8.213/91, como os art. 18 e 96 por impedirem a fruição plena dos direitos trabalhistas e, imporem multa de $10 \%$ e juros moratórios de $0,5 \%$ ao mês sobre cada ano que o contribuinte deseje contar para efeito de contribuição.

Até o início de 2015, o principal projeto em tramitação era o PL do Senado $n^{\circ}$ 91/2010, cuja autoria é do Senador Paulo Paim e pretende regulamentar o direito à desaposentadoria. Em que pese os avanços previstos, como a possibilidade de renúncia a qualquer tempo e a incidência sobre a aposentadoria especial e por idade, apresenta falhas que constituem um obstáculo para o trabalhador, sendo mais benéfico o modelo a ser julgado pelo STF. (BRASIL. 2010, p. 01).

Entre suas falhas está a não previsão de mudança de sistema, por tratar apenas do RGPS e, de grande prejuízo, a vedação de uso do tempo em que estava aposentado e contribuindo ao sistema na contagem da nova jubilação, o que pode inviabilizar o direito. Desta feita, o projeto representa um avanço tímido, porém de cunho retrocessivo, em direção a legalizar a desaposentação, mas é o primeiro passo para a transformação social.

Porém, ainda no primeiro semestre de 2015, o Congresso Nacional editou emenda parlamentar para eliminar o fator previdenciário, em seu lugar tentou estabelecer nova regra que fosse mais justa ao trabalhador e ao mesmo tempo garantisse o equilíbrio atuarial e fiscal, assim surgiu a regra 85-95 pela qual a soma da idade com o tempo de contribuição deve alcançar 85 para mulheres e 95 para homens, ou seja, para um homem se aposentar com 35 anos de contribuição, deve, obrigatoriamente, ter pelo menos 60 anos de idade.

No entanto o Executivo modificou a regra e editou a Medida Provisória n ${ }^{\circ}$ 676, de 17 de junho de 2015, pela qual criou uma progressividade, aumentando os valores anualmente até alcançar 90-100, já a partir de 2017. A nova regra foi mantida com pequena alteração em sua data de início e intervalos, após acordo entre os poderes, passando a contar em 2018 e modificação bianual. (ALEGRETTTI. 2015. p. 01)

Importante salientar que essa nova regra, segundo afirma Pinto (2015. p. 01), praticamente tornava nulo o debate sobre desaposentação, restando apenas regulamentar a questão da repetição de valores, isto devido a MP contemplar a desaposentação em seu texto, e esta devendo se dar nas novas regras, podendo ser mais benéfica para o trabalhador aposentado, 
Artigo original

Hegemonia - Revista Eletrônica do Programa de Mestrado em Direitos Humanos, Cidadania e Violência/Ciência Política do Centro Universitário Unieuro

ISSN: 1809-1261

UNIEURO, Brasília, número 22 (Especial), 2017, pp. 48-25.

visto que muitos já se encontram com mais de 5 anos de serviço pós aposentadoria e devem somar o binômio tempo idade, livrando-se do fator previdenciário e por consequência obtendo valor de aposentadoria nova aumentado.

A desaposentação chegou a constar no texto da MP depois de um acordo entre Legislativo e Executivo, que teve por base o fim do fator previdenciário, no entanto, o instituto posteriormente sofreu o veto presidencial, imergindo a real intenção do Executivo que sempre foi no sentido inverso à normatização, assim afirma Martinez (2014. p. 169), ao citar que a atuação do Executivo tem sido para vetar reformas do código e negando administrativamente o pedido dos contribuintes sob a alegação de incidência do ato jurídico perfeito, a necessidade de restituição dos valores recebidos, a possível incidência de enriquecimento ilícito, a impossibilidade jurídica do pedido, bem como o déficit previdenciário.

$\mathrm{Na}$ opinião do autor supra, a invocação pelo Estado do ato jurídico perfeito não pode ser usada, pois afetaria o direito do beneficiário em auferir melhora na sua renda, uma vez que essa melhora não consista em ilegalidade ou imoralidade (2014. p. 170). Quanto à afirmativa de necessidade de devolução dos valores auferidos, na visão jurídica o assunto já se encontra superado nos tribunais no sentido de ser verba irrepetível. Da mesma sorte, a possibilidade de caracterizar enriquecimento ilícito não deve prosperar, pois somente teria lugar se a concessão da aposentadoria estivesse eivada de vícios, o que denotaria anulação e não desaposentação.

A alegação de impossibilidade jurídica é superada pelo entendimento neoconstitucionalista da $\mathrm{CF} / 88$ que prima pelos princípios, nesse caso o da DPH. Ademais, como afirma Zarzana apud Ibrahim (2011. p.85.), a falta de previsão concedente dos direitos fundamentais deve ser interpretada como sua concessão, pois nesses casos, deve-se decidir sempre em favor da pessoa humana.

Ainda, na obra de Martinez (2014. p. 249.), encontra-se a alegação de que o equilíbrio atuarial e financeiro estaria sendo comprometido com a concessão de desaposentação. Esta afirmativa não tem razão de ser, pois o período trabalhado a ser incorporado para nova jubilação sofreu tributação previdenciária como qualquer outra fonte de renda, no entanto não tem mais o condão de formar fundo para futura aposentadoria.

Em relação ao alegado déficit, duas considerações devem ser feitas, a primeira quanto ao impacto nas contas públicas, posto que as revisões devam aumentar o repasse público por parte da previdência que já sofre, conforme alegações estatais, com forte déficit. A segunda, diz respeito à melhoria nas condições de vida do aposentado e, por conseguinte, de sua família, provocada pelo maior poder econômico. 
Artigo original

Hegemonia - Revista Eletrônica do Programa de Mestrado em Direitos Humanos, Cidadania e Violência/Ciência Política do Centro Universitário Unieuro

ISSN: 1809-1261

UNIEURO, Brasília, número 22 (Especial), 2017, pp. 48-25.

O governo alega a existência de um grande déficit previdenciário devido ao atual sistema de financiamento adotado, que tem operado com desequilíbrio. De fato, este déficit foi confirmado pelo ministro do Tribunal de Contas da União (TCU) Augusto Nardes, em palestra no Instituto Brasileiro de Mercado de Capitais (Ibmec), Rio de Janeiro, na qual ele informa que o déficit da Previdência deve chegar a R \$ 194,9 bilhões em 2016, sendo estimado para 2015 em $\mathrm{R}$ \$ 157,3 bilhões. A dívida está em crescente evolução, pois até 2012, o valor atingia $\mathrm{R} \$ 95,2$ bilhões, tendo mais que dobrado em 4 anos. (VIEIRA. 2015, p. 01).

No entanto, conforme Zarzana (2014. p. 62), não existe desequilíbrio e sim má aplicação dos recursos, uma vez que o governo desvia a finalidade do tributo para outras áreas politicamente mais rentáveis. Essa afirmação parece encontrar eco na referida palestra do ministro Nardes, já que em determinado momento declara que o programa Bolsa Família consiste em incentivo para as pessoas não trabalharem, logo, não contribuem para o setor formal, visto que os beneficiários apenas recebem valores e não vertem qualquer contribuição ao fundo previdenciário, fazendo jus, mais tarde, ao benefício previdenciário por idade.

Por mais que atualmente exista um rombo nas contas, a total impossibilidade de pagamento alegada pelo governo, em caso de aprovação da desaposentação, não parece ser real. Estudo apresentado por Zanella, Carvalho e Afonso (2014, passim), chegou à conclusão que existe um período ótimo para desaposentação, sendo este variável de acordo com o salário base e o sexo.

Para os homens, em todas as faixas salariais, o tempo ideal seria de 5 anos após a aposentação, pois quanto mais postergar essa desaposentação mais próximo estará do teto previdenciário e menor sua expectativa de vida, ou seja, a demora anula o ganho. No caso das mulheres, a expectativa de vida influência na faixa salarial. Mulheres com 5 salários mínimos iniciais encontram o tempo ideal a partir de 8 anos da aposentação ao passo que as da faixa de 1 salário somente podem pedir a desaposentação passados 10 anos. Fora desses prazos não há vantagem pecuniária.

Considerando a possibilidade de devolução dos valores recebidos durante o período de aposentadoria, nenhum homem poderia requerer a desaposentação, pois o prazo para retorno seria maior que sua expectativa de vida. Segundo o estudo, em média o segurado deveria viver entre 13 e 22 anos após o pedido de desaposentação para ver surtir algum benefício. Assim, por mais que aumente o repasse, nem todas as pessoas teriam vantagem com a desaposentação e o período para pedido possibilita rearranjos na previdência. Ademais, a expectativa de vida torna o prazo de pagamento diminuto e o impacto nas contas minorado. 
Artigo original

Hegemonia - Revista Eletrônica do Programa de Mestrado em Direitos Humanos, Cidadania e Violência/Ciência Política do Centro Universitário Unieuro

ISSN: 1809-1261

UNIEURO, Brasília, número 22 (Especial), 2017, pp. 48-25.

O segundo ponto a verificar é o impacto na vida do aposentado. Assim como no Bolsa Família, melhor remuneração implica em melhores condições sociais, refletindo principalmente nas áreas da saúde, alimentação, lazer e moradia. Bem certo que os valores concedidos nos programas sociais acabam voltando aos cofres públicos por fazer girar a economia, sendo, na reportagem de Lorenza (2011. p. 01), o retorno na forma de impostos e atingindo a ordem de 56\% do valor investido, impactando no Produto Interno Bruto (PIB) nada menos que $\mathrm{R}$ \$23,7 bilhões. No entanto, a desaposentação representa ainda mais ganho para o governo visto que há aporte durante todo período trabalhado e, igualmente ao programa social, implica em menores gastos diretos nos vários setores sociais com retorno na forma de impostos.

Há ainda que se considerar que uma pessoa aposentada que retorna à situação de ativa, acaba por ocupar a vaga de um jovem impedindo seu ingresso no mercado de trabalho formal, obrigando a recorrer a "bicos" para sobreviver. Essa informalidade, normalmente, não verte valores aos cofres da previdência e cria um circulo vicioso que levara, mais tarde, a busca pelo chamado benefício previdenciário, valor pago a quem não contribuiu, mais recebe valores da previdência em decorrência do DPH. Na prática, aumento no déficit público.

Uma vez que a MP ainda não regulamenta completamente a questão e, a espera de acordo entre o Legislativo e o Executivo é demasiada longa, segue o Poder Judiciário legislando sobre o tema e concedendo vitórias ao trabalhador, mesmo o assunto não estando pacificado nesse poder, visto que os tribunais superiores concedem o pedido, mas os tribunais de entrada o têm negado.

No aguardo do pronunciamento do STF, adota-se como norteador o posicionamento do STJ, que tem decidido pela desnecessidade de devolver os valores percebidos e com a possibilidade de contagem do tempo anterior e posterior à aposentação na concessão de novo benefício. Essa é a opinião do Ministro Marco Aurélio que prega ser "realmente o lado correto, o lado do povo tributado por demais e assistido por muito menos" (2014.p.70).

Apesar desse posicionamento do ministro o caminho não será tão suave quanto pode parecer, pois dentro do mesmo STF, o Ministro Ricardo Lewandowski é voz contrária à desaposentação, defendendo o entendimento de ofensa ao ato jurídico perfeito (2014, p.71).

Dos recursos que esperam julgamento no STF, o mais relevante para os administrados é o RE 381.367, sob relatoria do Ministro Marco Aurélio, já que o ministro votou favoravelmente à concessão, expressando raciocínio similar a Salvador (2012, p. 106) ao defender ser a desaposentação medida de justiça consistente na renúncia à condição de aposentado, mas 
Artigo original

Hegemonia - Revista Eletrônica do Programa de Mestrado em Direitos Humanos, Cidadania e Violência/Ciência Política do Centro Universitário Unieuro

ISSN: 1809-1261

UNIEURO, Brasília, número 22 (Especial), 2017, pp. 48-25.

não ao tempo de serviço. Aliás, assevera Zarzana (2014, p. 80) que o uso desse tempo depende da vontade do trabalhador, portanto, direito disponível.

Já os juristas apoiadores da visão do Ministro Lewandowski alegam a necessidade de manter o equilíbrio atuarial e financeiro, a previsão da Lei 8213/91 e o princípio da legalidade implícito no art. $5^{\circ}$, da CF/88. Para estes, os valores pagos são parte da reserva construída ao longo dos anos de contribuições e o regime estaria preparado para ceder certo valor ao aposentado, qualquer alteração acarretaria prejuízo à sociedade. Neste entendimento, Kravchychyn (2008, p. 05.) cita julgado do TRF-3 que considera lícita a desaposentação se ocorrer a devolução de valores, negligenciando eles o princípio judicial da precedência condicionada.

Quanto à falta de previsão legal, alegam que o Estado somente pode agir em virtude de lei, no entanto, o uso dos direitos individuais não necessita prévia cominação legal, é devido e permitido imediatamente, não sendo lícito ao Poder Público vetar o acesso a esses direitos. Conforme declara Kravchychyn (2008. p. 04) na "ausência de expressa proibição legal, subsiste a permissão, posto que a limitação da liberdade individual deva ser tratada explicitamente, não podendo ser reduzida ou diminuída por omissão."

Para Zarzana (2014, p. 82) a desaposentação promove a DPH, sendo "direito de o beneficiário buscar uma situação financeira que lhe permita viver de forma a alcançar um patamar mais digno de sobrevivência”. A busca pela sobrevivência digna é direito das pessoas, consubstanciado no princípio da DPH e, obrigá-lo a receber um valor baixo sob a argumentação de que a melhora ofenderia o ato jurídico perfeito e o direito adquirido, nada mais é que ofender esses mesmos institutos.

Diante do exposto, considerando-se as palavras do Ministro Marco Aurélio, é de se crer que a tendência do Poder Judiciário caminha ao encontro dos anseios da sociedade que continua labutando, mesmo após ter deferida a aposentadoria.

\section{CONSIDERAÇÕES FINAIS}

Em verdade não existe legislação nacional que institua explicitamente a desaposentação, sendo ela uma construção jurídica baseada na interpretação da CF/88 e legislação infraconstitucional geral e específica. Não obstante a isso, inegável se torna representar a concretização dos anseios da sociedade, principalmente dos aposentados que ainda labutam, 
Artigo original

Hegemonia - Revista Eletrônica do Programa de Mestrado em Direitos Humanos, Cidadania e Violência/Ciência Política do Centro Universitário Unieuro

ISSN: 1809-1261

UNIEURO, Brasília, número 22 (Especial), 2017, pp. 48-25.

recolhem impostos como quaisquer outros filiados ao RGPS, mas não possuem as mesmas garantias trabalhistas, ofendendo assim ao princípio da isonomia.

A contribuição dos trabalhadores forma o fundo que pagará os benefícios dos jubilados e pensionistas, no entanto, o já aposentado que continua vertendo valores para o fundo não se encaixa nessa sistemática, isso porque a lógica é a geração atual pagar o benefício da pretérita, mas esse trabalhador pertence às duas gerações concomitantemente.

Diferentemente de países como Canadá, Portugal e Chile, onde os valores vertidos após a jubilação recalculam anual e automaticamente o benefício, até atingir um teto estabelecido em lei, no Brasil, o aposentado que volta a produzir deve contribuir, sem poder melhorar sua renda. Nesse cenário surge a desaposentação, cujo objetivo é justamente permitir que o aposentado possa continuar a produzir por mais alguns anos e, posteriormente, melhorar o valor de sua aposentadoria, usufruindo de uma renda melhor na inatividade.

Vozes contrárias classificam tal manobra como amoral, prejudicial ao equilíbrio atuarial e financeiro, contrária ao ato jurídico perfeito, bem como ilegal por constituir enriquecimento ilícito, no entanto, os argumentos apresentados não resistem quando contrapostos à $\mathrm{CF} / 88$ que pugna por garantir os direitos humanos, dentre eles os da DPH.

A dignidade se encontra na garantia da justa retribuição pelo trabalho logo, ao cobrar dos aposentados que retornam à ativa contribuição previdenciária igual a dos demais trabalhadores e negar similares direitos, o Estado age de modo discriminatório, imoral e até perverso, por manter o administrado abaixo da linha social a que tem direito e contribuiu.

No quesito enriquecimento ilícito, ficou demonstrado que o argumento é falho, uma vez que a concessão inicial obedeceu a todos os requisitos da lei, somente podendo levantar a bandeira de ilicitude se o ato concedente estivesse eivado de vícios. Neste mesmo sentido, negase a devolução dos valores recebidos, uma vez que o foram licitamente, possuem natureza alimentar e tal obrigação tornaria inviável a fruição do direito pretendido.

Nos poderes constituídos, verificava-se uma tendência à aprovação da desaposentação no legislativo, que o fez constar na MP nº 676, de 17 de junho de 2015, mesmo carente de regulamentação, mas encontra forte resistência no Executivo. No entanto, a depender do Judiciário, que apenas espera pacificação pelo STF, o sistema será implantado, principalmente quando se analisa as declarações do ministro relator que vota favorável aos pedidos dos contribuintes. Essa postura parece ser a mais lógica, uma vez que até mesmo o Tribunal de Contas da União defende que a desaposentadoria é direito do administrado, apenas 
Artigo original

Hegemonia - Revista Eletrônica do Programa de Mestrado em Direitos Humanos, Cidadania e Violência/Ciência Política do Centro Universitário Unieuro

ISSN: 1809-1261

UNIEURO, Brasília, número 22 (Especial), 2017, pp. 48-25.

aperfeiçoando uma relação já existente. Essa querela já estaria praticamente resolvida não fosse o veto presidencial ao instituto da desaposentação, previsto em acordo na MP supra citada.

A busca na melhora das condições de vida sensibilizou, também, o Legislativo, acarretando a propositura de vários projetos, com o fito de regulamentar definitivamente o instituto, no entanto, o consenso político ainda representa importante entrave nas votações.

O estudo apresentado pela Isto É revela que o número de idosos, aposentados, no mercado de trabalho, tornou-se crescente. Essa massa de trabalhadores contribui normalmente para a Previdência e já engloba o grupo que recebe valores da mesma Previdência, então, teoricamente, seria como se o Fundo recebesse de uma gama de trabalhadores que iria falecer antes de se aposentar, ou seja, os valores não teriam destinatários.

Esse fato agrega um superávit à Previdência, impondo ao trabalhador uma obrigação, sem prever uma retribuição compensatória, podendo caracterizar enriquecimento ilícito por parte do Estado. Ora, como o reaposentado tem idade mais avançada, sua expectativa de vida é menor que a do recém-aposentado, por conseguinte, representará peso minimizado à Previdência Social, sendo ilógico o temor de provocar desequilíbrio financeiro, uma vez que contribuiu por tempo maior com o Fundo.

Salienta-se que poucas pessoas conseguem atingir o teto previdenciário e aqueles o que o lograram estarão impedidos, por lei vigente, de requerer reaposentação, ademais, segundo estudo apresentado por Zanella, Carvalho e Afonso, o aposentado masculino teria de esperar 5 anos para poder requere nova aposentação, antes ou após esse prazo a revisão acarretaria prejuízo ao contribuinte, no caso das mulheres o prazo seria de 8 a 10 anos em virtude da expectativa de vida. O mesmo estudo aponta que se for deferida a devolução dos valores recebidos, o aposentado teria de viver de 13 a 22 anos após requerer a desaposentação para poder sentir alteração benéfica nos rendimentos, o que torna inviável o instituto. Portanto, o possível desequilíbrio atuarial e financeiro mitiga-se por imposição legal prévia em relação ao teto, por menor tempo de vida após a concessão da desaposentação e pelo fato da maioria dos aposentados terem contribuído com taxa calculada sobre 1 salário mínimo, para os quais a desaposentação após 5 ou 10 anos não representa grande mudança.

Quando foi criada a sistemática do INSS, a realidade brasileira era bem diferente da atualidade, o Brasil era uma nação jovem e a expectativa de vida baixa, hoje a população está envelhecida e a expectativa de vida chega perto dos 80 anos. Mais que um problema monetário, a readequação da previdência é uma questão de gestão, não sendo justo transferir ao trabalhador as 
Artigo original

Hegemonia - Revista Eletrônica do Programa de Mestrado em Direitos Humanos, Cidadania e Violência/Ciência Política do Centro Universitário Unieuro

ISSN: 1809-1261

UNIEURO, Brasília, número 22 (Especial), 2017, pp. 48-25.

mazelas provocadas pela falha administrativa governamental que não consegue atualizar a estrutura ultrapassada da previdência.

Diante do exposto, constata-se como moral, ético, viável, justo e legal a adoção, pelo Brasil, do instituto da desaposentação, restando ao Legislativo derrubar o veto presidencial no tocante à desaposentação, bem como prever suas regras, normatizando a MP nº 676, de 17 de junho de 2015, em especial, quanto à contagem de tempo e restituição de valores, produzindo justiça social.

\section{REFERÊNCIAS}

ALEGRETTI. Laís. Senado aprova novas regras para aposentadoria e 'desaposentação'. Do G1, Brasília. 07/10/2015. 18h11min. Disponível em: <http://g1.globo.com/economia/noticia/2015/10/senado-aprova-regra-progressiva-para-obteraposentadoria.html>. Acesso em 31 out 2015.

AMORIM, José Roberto Neves. Tipos de aposentadorias - auxílios - pensões - salário família salário maternidade.

Disponível

em:

$<$ http://www.professoramorim.com.br/home/index.php?option=com_content\&view=article\&i $\mathrm{d}=338$ :tipos-de-aposentadorias-aux $\% \mathrm{C} 3 \% \mathrm{AD}$ lios-pens $\% \mathrm{C} 3 \% \mathrm{~B} 5 \mathrm{es}-\mathrm{sal} \% \mathrm{C} 3 \% \mathrm{~A} 1$ riofam $\% \mathrm{C} 3 \%$ ADlia-sal $\% \mathrm{C} 3 \%$ A1 rio-maternidade\&catid=25: direito-previdenciario $\&$ Itemid $=79>$. Acesso em 19 mar 15.

BRASIL. CLT. Decreto-Lei $\mathrm{n}^{\circ}$ 5452, de $1^{\circ}$ de maio de 1943. Disponível em:<http://www.planalto.gov.br/ccivil_03/decreto-lei/del5452.htm>. Acesso em 22 mar. 15.

$$
\text { Aposentadoria por idade. Disponível em: }
$$

<http://www.inssaposentadoria.com/aposentadoria-idade/>. Acesso em 19 mar 15.

$$
\text { Aposentadoria especial. Disponível }
$$
em:<http://www.inssaposentadoria.com/aposentadoria-especial/>. Acesso em 19 mar 15.

$$
\text { Aposentadoria por invalidez. Disponível em: }
$$

<http://www.inssaposentadoria.com/aposentadoria-por-invalidez/>. Acesso em 19 mar 15.

Aposentadoria por tempo de contribuição. Disponível em: $<$ http://www.inssaposentadoria.com/aposentadoria-por-tempo-de-contribuicao/>. Acesso em $19 \operatorname{mar} 15$.

Tipos de aposentadoria. Disponível em: <http://www.inssaposentadoria.com/tipos-deaposentadoria/>. Acesso em 19 mar 15. 
Artigo original

Hegemonia - Revista Eletrônica do Programa de Mestrado em Direitos Humanos, Cidadania e Violência/Ciência Política do Centro Universitário Unieuro

ISSN: 1809-1261

UNIEURO, Brasília, número 22 (Especial), 2017, pp. 48-25.

JEF. PEDILEF nº 200872580022929- Seção Judiciária de Santa Catarina-SC, Turma

Nacional de Uniformização dos Juizados Especiais Federais, Relator Juiza Jacqueline Michels

Bilhalva, 2010, DJE de 8-4-2010. Disponível em: <http:// http://jurisprudencia.s3.amazonaws.com/TNU/IT/PEDILEF_200872580022929_SC_1277321 366336_1.pdf?Signature $=\mathrm{MkxqP} 6 \mathrm{ydE} \% 2 \mathrm{BStnDPv} \% \% 2 \mathrm{FSn} \% 2 \mathrm{Fx} 4 \mathrm{dINA} \% 3 \mathrm{D} \&$ Expires $=142713$ 2174\&AWSAccessKeyId=AKIAIPM2XEMZACAXCMBA\&response-contenttype=application/pdf\&x-amz-meta-md5-hash=9a716d5737d7c629a5844048c514248b>. Acesso em 20 mar 15.

EDcl nos EDcl no AgRg no REsp 1271891/RS, Rel. Ministro Newton Trisotto (Desembargador convocado do TJ/SC), Quinta Turma, julgado em 03/03/2015, DJe $10 / 03 / 2015$.

Disponível

em:

$<$ http://www.stj.jus.br/SCON/jurisprudencia/toc.jsp?tipo_visualizacao $=$ null\&livre $=$ devolu $\% \mathrm{E}$ $7 \% \mathrm{E} 3 \mathrm{o}+\mathrm{de}+$ aposentadoria\&b=ACOR\&thesaurus=JURIDICO\#DOC1>. Acesso em 29 mar 2015

Lei no 8.112, de 11 de dezembro de 1990. Regime jurídico dos servidores públicos da União, das autarquias e das fundações públicas federais. Disponível em: <http://www.planalto.gov.br/ccivil_03/leis/18112cons.htm>. Acesso em 22 mar 2015.

Lei $\mathrm{n}^{\circ}$ 8.213, de 24 de julho de 1991. Disponível em: <http://www.planalto.gov.br/ccivil_03/leis/18213cons.htm>. Acesso em 14 mar 15.

Ministério da Previdência Social. Entidade Fechada de Previdência Complementar -

EFPC. Disponível em < http://www.previdencia.gov.br/previc/entidade-fechada-de-previdnciacomplementar-efpc/>. Acesso em 14 mar 2015

- Ministério da Previdência Social. Fator previdenciário. Disponível em: < http://www.previdencia.gov.br/informaes-2/fator-previdencirio-2/>. Acesso em 22 mar. 15.

O que é Previdência Complementar. Disponível em: <http://www.previdencia.gov.br/a-previdencia/previdencia-complementar/o-que-previdnciacomplementar/>. Acesso em 10 mar 2015

Previdência Associativa / Instituidor. Disponível em <http://www.previdencia.gov.br/previc/previdncia-associativa-instituidor/>. Acesso em 14 mar 2015

Regime Geral - RGPS. Disponível em:<http://www.previdencia.gov.br/ouvidoriageral-da-previdencia-social/perguntas-frequentes/regime-geral-rgps/>. Acesso: 10 mar 2015. 
Artigo original

Hegemonia - Revista Eletrônica do Programa de Mestrado em Direitos Humanos, Cidadania e Violência/Ciência Política do Centro Universitário Unieuro

ISSN: 1809-1261

UNIEURO, Brasília, número 22 (Especial), 2017, pp. 48-25.

STF. RE 591.467-AgR, Rel. Min. Gilmar Mendes, 2012, Segunda Turma, DJE de 25-42012. Disponível em: <http://www.stf.jus.br/portal/constituicao/artigo.asp\#ctx1>. Acesso em 09 mar 15.

STJ. AgRg no REsp 1240362-SC, Rel. Min. Desembargador Convocado do TJ-SP Celso Limongi, 2011, Sexta Turma, julgado em 3-5-2011, DJE de 25-4-2012. Disponível em: <http://www.plenum.com.br/ac/stj/002/201100966297_20110624.pdf>. Acesso em 19 mar 15.

STJ. AgRg no REsp 926.120-RS, DJe 8/9/2008, e AgRg no REsp 328.101-SC, DJe 20/10/2008. REsp 1.113.682-SC, Rel. originário Min. Napoleão Nunes Maia Filho, Rel. para acórdão Min. Jorge Mussi, julgado em 23/2/2010.

.STJ . AgRg no REsp: 1308016 PR 2012/0021433-3, Relator: Ministro OG FERNANDES, Data de Julgamento: 10/12/2013, T2 - SEGUNDA TURMA, Data de Publicação: DJe 18/12/2013. Disponível em: < http://stj.jusbrasil.com.br/jurisprudencia/24829696/agravo-regimental-no-recurso-especialagrg-no-resp-1308016-pr-2012-0021433-3-stj>. Acesso em 03 mai 2015.

.STJ . EDecl no AgRg no REsp n. 1.334.488/SC, Rel. Ministro Herman Benjamin, Primeira Seção, julgado em 08/05/2013, Data de Publicação: DJe 13/5/2014. Disponível em: http://www.jusbrasil.com.br/jurisprudencia/busca?q=titulo\%3AREsp+1.334.488\%2FSC.

.TJ-RS - AC: 70051118461 RS, Relator: Bayard Ney de Freitas Barcellos, Data de Julgamento: 25/09/2013, Décima Primeira Câmara Cível, Data de Publicação: Diário da Justiça do dia 27/09/2013. Disponível em: <http://tjrs.jusbrasil.com.br/jurisprudencia/113293728/apelacao-civel-ac-70051118461-rs>. Acesso em 03 mai 15.

.TRF-2 - APELREEX: 201051018125284 RJ 2010.51.01.812528-4, Relator: Desembargador Federal Paulo Espirito Santo, Data de Julgamento: 31/01/2012, Primeira Turma Especializada, Data de Publicação: E-DJF2R - Data:14/02/2012 - Página::97. Disponível em: $<$ http://trf-2.jusbrasil.com.br/jurisprudencia/21298584/apelacao-reexame-necessario-apelreex201051018125284-rj-20105101812528-4-trf2>. Acesso em 03 mai 2015.

TRF-3 - AC: 57436 SP 95.03.057436-6, Relator: JUIZ FERNANDO GONCALVES, Data de Julgamento: 31/07/2007, Data de Publicação: DJU DATA:05/09/2007 PÁGINA: 614). TRF-4. Processo no 2004.92.95.003417-4, Relator Juiz Ivori Luis da Silva Scheffer, 2004, - Turma Recursal da Seção Judiciária de Santa Catarina, DJE de 5-8-2004. Disponível em: <http://www.tfsc.gov.br>. Acesso em 20 mar 15. 
Artigo original

Hegemonia - Revista Eletrônica do Programa de Mestrado em Direitos Humanos, Cidadania e Violência/Ciência Política do Centro Universitário Unieuro

ISSN: 1809-1261

UNIEURO, Brasília, número 22 (Especial), 2017, pp. 48-25.

CARVALHO, Gilvan Nogueira. Introdução ao direito previdenciário: os regimes de previdência. In: Âmbito Jurídico, Rio Grande, XV, n. 98, mar 2012. Disponível em: < http://www.ambitojuridico.com.br/site/index.php?n_link=revista_artigos_leitura\&artigo_id=11265>. Acesso em 14 mar 2015.

CHILE. Decreto-Lei 3.500, de 4 de novembro de 1980. Disponível em:<http://www.leychile.cl/Navegar?idNorma=7147\&r=3>. Acesso em 11 de abril de 2015.

COLNAGO, Lorena de Mello Rezende. Desaposentação. Revista de Previdência Social, São Paulo, n. 301, p. 784-793, dez. 2005.

DIAS, Clara Angélica Gonçalves. A Responsabilidade Civil do Empregador Diante dos Riscos Sociais que Afetam a Saúde e a Integridade Física do Empregado. Tese em Doutorado. Orientador Prof Carla Teresa Martins Romar. 2010. PUC. Disponível em: $<$ http://www.dominiopublico.gov.br/download/teste/arqs/cp144080.pdf>. Acesso em 20 jun 2015.

$\begin{array}{llll}\text { Dicionário } & \text { Aurélio. } & \text { Aposentadoria. } & \text { Disponível }\end{array}$ em:<http://www.dicionariodoaurelio.com/aposentadoria>. Acesso em 22 mar 15.

Dicionário Priberam da Língua Portuguesa, Aposentadoria, 2008-2013. Disponível em: <http://www.priberam.pt/DLPO/aposentadoria>. Acesso em 22 mar 15.

DINIZ, Maria Helena. Dicionário jurídico. São Paulo: Saraiva, 1998, p.36.

FIOCRUZ. Aposentadoria.

Disponível em:

$<$ http://www.direh.fiocruz.br/manual/novo_manual/?id=14\&m=beneficios\&s=aposentadoria \&i=compulsoria.htm>. Acesso em 19 mar 15.

Fundação de Previdência Complementar do Servidor Público Federal do Poder Executivo (Funpresp). Diferenças entre RPPS e RGPS. Disponível em: <http://www.funpresp.com.br/portal/?page_id=16>. Acesso em 15 mar 2015.

GuIMARÃES, Deocleciano Torrieri. Dicionário Técnico Jurídico. 13. ed. São Paulo: Rideel, 2010.

HOMCI, Arthur Laércio. A EVOLUÇÃO HISTÓRICA DA PREVIDÊNCIA SOCIAL NO BRASIL. Jus Navigandi, Teresina, ano 14, n. 2104, 5 abr. 2009. Disponível em: <http://jus.com.br/artigos/12493>. Acesso em 19 mar 2015.

IBRAHIM, Fábio Zambitte. Desaposentação: o caminho para uma melhor aposentadoria. 5 ed., Niteroi-RJ: Impetus, 2011. 
Artigo original

Hegemonia - Revista Eletrônica do Programa de Mestrado em Direitos Humanos, Cidadania e Violência/Ciência Política do Centro Universitário Unieuro

ISSN: 1809-1261

UNIEURO, Brasilia, número 22 (Especial), 2017, pp. 48-25.

KRAVCHYCHYN, Gisele Lemos. DESAPOSENTAÇÃO - fundamentos jurídicos, posição dos tribunais e análise das propostas legislativas. Disponível em: <http://www.jurisway.org.br/v2/dhall.asp?id_dh=559>. Acesso em 29 mar 2015.

LIMA, Marcos Galdino de. O instituto da desaposentação. In: Âmbito Jurídico, Rio Grande, XIII, n. 78, jul 2010. Disponível em: $<$ http://www.ambitojuridico.com.br/site/index.php?n_link=revista_artigos_leitura\&artigo_id= 7952>. Acesso em 29 mar 2015.

LORENZI, Sabrina. Gasto com Bolsa Família aumenta PIB em R \$23,7 bi. iG Rio deJaneiro. Disponível em: < http://economia.ig.com.br/gasto-com-bolsa-familia-aumenta-pib-em-r-237bi/n1238126027945.html>. Acesso em 01 out. 2015

MACEDO, Wilson Teles de. Parecer: Servidor Público - Aposentadoria - Renúncia. RDA-RJ, n. 210, p. 309-316, out./dez. 1997. P. 316 apud COLNAGO, Lorena de Mello Rezende. Desaposentação. Revista de Previdência Social, São Paulo, n. 301, p. 793, dez. 2005.

MARTINEZ, Wladimir Novaes. Desaposentação. 6. ed., São Paulo: LTr, 2014.

MARTINEZ, Wladimir Novaes. Pressupostos lógicos da desaposentação. Revista de Previdência Social, São Paulo, n. 296, p.434, jul, 2005.

MEZZAROBA, Orides; MONTEIRO, Cláudia Servilha. Manual de metodologia da pesquisa no direito. 3. ed. rev. São Paulo: Saraiva, 2006.

ONGARATTO, Vinícius. Ato jurídico perfeito, coisa julgada e direito adquirido. In: Âmbito Jurídico, Rio Grande, XIII, n. 81, out 2010. Disponível em: <http://www.ambitojuridico.com.br/site/?n_link=revista_artigos_leitura\&artigo_id $=8805 \&$ revista_caderno $=2>$.

Acesso em 29 mar 2015.

PIEROTTI, Wagner de Oliveira. A desaposentação e a revisão do benefício previdenciário. Disponível em:< http://ojs.fsg.br/index.php/direito/article/viewFile/245/213>. Acesso em 02 abri 15.

PINTO. Jose Luiz da Silva. Como fica a desaposentação com a nova regra 85-95?. Disponível em: < http://joseluizsp.jusbrasil.com.br/artigos/218335880/como-fica-a-desaposentacao-coma-nova-regra-85-95>. Acesso em 31 out 2015.

PORTAL BRASIL. Confira os tipos de aposentadoria existentes no Brasil. 30 jul. 2014. Disponível em: <http://www.brasil.gov.br/economia-e-emprego/2014/05/confira-os-tipos-deaposentadoria-existentes-no-brasil>. Acesso em 19 mar 15.

REVISTA DO CURSO DE DIREITO DA FSG. 200, ano 3, n. 5, jan./jun. 2009 
Artigo original

Hegemonia - Revista Eletrônica do Programa de Mestrado em Direitos Humanos, Cidadania e Violência/Ciência Política do Centro Universitário Unieuro

ISSN: 1809-1261

UNIEURO, Brasília, número 22 (Especial), 2017, pp. 48-25.

ROCHA, Daniel Machado. O direito fundamental à previdência social: na perspectiva dos princípios constitucionais diretivos do sistema previdenciário brasileiro. Porto Alegre: Livraria do Advogado, 2004.

; BALTAZAR JÚNIOR, José Paulo. Comentários à lei de benefícios da previdência social. Porto Alegre: Livraria do Advogado, 2004.

SALVADOR, Sérgio Henrique. A desaposentação e a teoria escisionista do direito previdenciário. Jornal Trabalhista Consulex, Brasília-DF, n. 1362, p.8, fev., 2011.

SALVADOR, Sérgio Henrique; AGOSTINHO, Theodoro Vicente. Desaposentação: aspectos teóricos e práticos - incluindo modelo de petição inicial. São Paulo: LTr, 2014.

SILVA, De Plácido e. Vocabulário Jurídico. 17. ed. Rio de Janeiro: Editora Forense, 2000.

SOARES, Victor. Tipos de previdência. Disponível em: <http://www.brasil.gov.br/economia-eemprego/2012/04/tipos-de-previdencia>. Acesso em 14 mar 15.

SOUZA, Peterson de. Desaposentação: possibilidades e limites. Leme-SP: Imperium Editora 2015.

- Desaposentação. Possibilidades e limites. Imperium. Ramos Prev. Consultoria.

Atualidades sobre a desaposentação. Disponível em:

$<$ http://ramosprev.jusbrasil.com.br/artigos/114271407/atualidades-sobre-a-desaposentacao>.

Acesso em 29 mar 2015.

VIANNA, João Ernesto Aragonés. Curso de direito previdenciário. 7. ed, São Paulo: Editora Atlas, 2014.

VIEIRA, Isabela. Nardes diz que déficit da Previdência iguala Brasil à Grécia e a Portugal. Agência Brasil. 29/10/2015. 18h29min. Disponível em: <http://agenciabrasil.ebc.com.br/politica/noticia/2015-10/nardes-diz-que-deficit-daprevidencia-iguala-brasil-grecia-e-portugal>. Acesso em 29 out. 2015.

ZARZANA, Dávio Antonio Prado. Desaposentação: passo a passo. Rio de Janeiro: Elsevier, 2014.

ZANELLA, Angelo José; CARVALHO, João Vinícius de França; AFONSO, Luís Eduardo. Quais os impactos da desaposentação? Um estudo para as aposentadorias por tempo de contribuição do regime geral de previdência social. Estud. Econ., São Paulo, v. 44, n. 4, p. 723748, dez. 2014.

em:

$<$ http://www.scielo.br/scielo.php?script=sci_arttext\&pid=S0101-

41612014000400003\&lng=pt\&nrm=iso >. Acessos: em 30 out. 2015. 